\title{
A Multi Evaporator Desalination System Operated with Thermocline Energy for Future Sustainability
}

\author{
Muhammad Wakil Shahzad, Muhammad Burhan, Noreddine Ghaffour and Kim Choon Ng* \\ ${ }^{1}$ King Abdullah University of Science and Technology (KAUST), Water Desalination and Reuse Center (WDRC), \\ Biological and Environmental Science \& Engineering (BESE), Thuwal 23955-6900, Saudi Arabia \\ Muhammad.shahzad@kaust.edu.sa, Muhammad.burhan@kaust.edu.sa, \\ noreddine.ghaffour@kaust.edu.sa and *kim.ng@kaust.edu.sa
}

\begin{abstract}
All existing commercial seawater desalination processes, i.e. thermally-driven and membranebased reverse osmosis (RO), are operated with practical performance ratios (PPRs) varying up to 90, whilst the PPR for an ideal or thermodynamic limit (TL) of desalination is at 828. Despite slightly better PPRs for the RO plants, all practical desalination plants available, hitherto, operate at only less than $11 \%$ of the TL, rendering them highly energy intensive and unsustainable for future sustainability. More innovative desalination methods must be sought to meet the needs of future sustainable desalination and these methods should attain an upper PPR bound of about 25 to $30 \%$ of the TL. In this paper, we examined the efficacy of a multi-effect distillation (MED) system operated with thermocline energy from the sea; A proven desalination technology that can exploit the narrow temperature gradient of $20^{\circ} \mathrm{C}$ all year round created between the warm surface seawater and the cold-seawater at depths of about 300-600 m. Such a seawater thermocline (ST)-driven MED system, simply called the ST-MED process, has the potential to achieve up to 2 folds improvement in desalination efficiency over the existing methods, attaining about $18.8 \%$ of the ideal limit. With the major energy input emanated from the renewable solar, the ST-MED is truly a "green desalination" method of low global warming potential, best suited for tropical coastal shores having bathymetry depths of $300 \mathrm{~m}$ or more.
\end{abstract}

Keywords: Multi-Effect distillation, Sustainable desalination, Renewable energy, Thermocline energy, Practical performance ratio. 


\section{1- Introduction}

All commercially available seawater desalination processes, hitherto, are operated far from the ideal efficiency or thermodynamic limit (TL). Consequently, the existing desalination processes are deemed energy intensive and unsustainable energetically for future desalination, as well as the inevitable associated $\mathrm{CO}_{2}$ emission arising from the high electricity consumption [1]. The TL of practical performance ratio (PPR) for seawater desalination processes is estimated as 838 by the minimum work input of $0.78 \mathrm{kWh} / \mathrm{m}^{3}$ and this ideal work is equivalent to the primary energy. The TL for desalination is independent of the desalting processes used but it is a function of initial concentration and temperature of feed water which has been defined as the ratio of energy needed to evaporate the feed water to the primary fossil energy input. Hitherto, the conventional PR of a desalination process has been expressed in terms of the derived energy, such as electricity or thermal energy, instead of the primary energy of fuel types, as shown in Figure 1. The use of derived energy in PR assessment is acceptable when the conversion technologies have a single useful effect output, i.e., a fossil fuel fired plant for electricity or a boiler for steam production. However, today's widespread use of cogeneration processes to produce electricity, steam and water simultaneously need more accurate method to distinguish the fraction of primary energy input consumed by the processes for their generation. The misperception in transforming the derived energy back to the primary energy input arises from the use of same units of energies (Joule or $\mathrm{kW}$ ) in quantifying the useful effects without differentiating the grade of energy consumed. The detailed explanation of the conversion methodology is delineated in Appendix 1 [2].

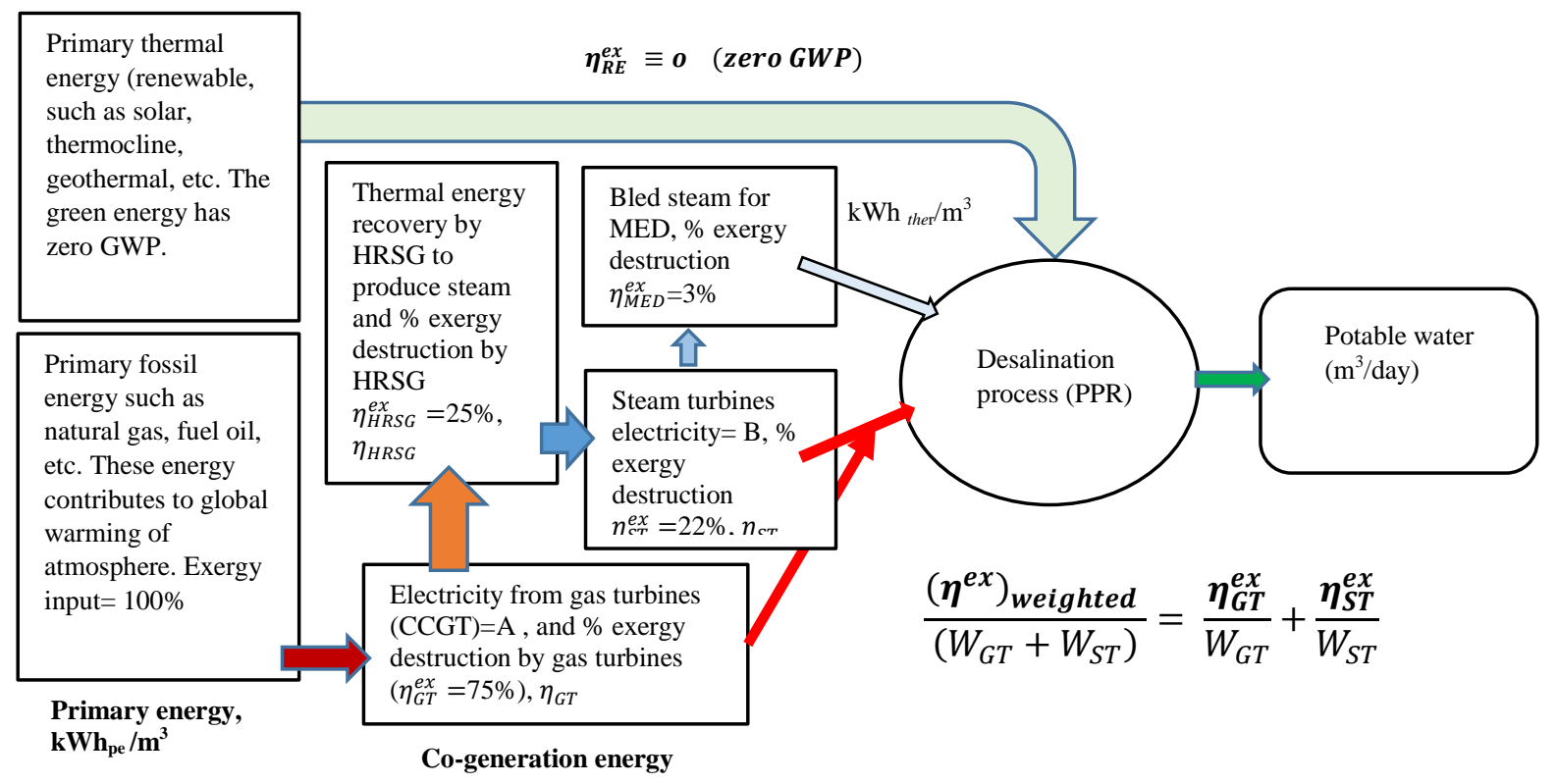

Figure 1: The distinction between primary and derived energy in desalination processes is a function of both the exergy utilization ( $\left.\eta_{\mathrm{i}}^{\mathrm{ex}}\right)$ and the conversion efficiency $\eta_{i}$ of the processes. The efficacy of a desalination plant is defined by the proposed practical performance ratio (PPR) which is based on the universal primary energy input that contributes directly to global warming of the atmosphere. 
To meet the goals of sustainable desalination, we proposed practical performance ratio (PPR) by incorporating two important factors to improve the conventional PR definition: Firstly, conversion of all derived energies utilized by the desalination processes to the primary energy by the fraction of exergy destruction by desalination processes and incorporating primary energy for PR calculation and input fuel apportionment. Secondly, only the primary energy consumed that has a direct consequence to global warming will be considered. This implies that renewable energies such as solar and geothermal or thermocline, non-polluting energies, utilized by desalination processes will have zero contribution to carbon emission and hence, it can be omitted in the PPR computation and this is aligned with the goal of sustainable desalination. This improved PPR definition, besides embodying environmental aspects of primary energy usage, provides a platform for cross comparison of assorted desalination methods. Table 1 depicts the typical values of the energy input to assorted desalination processes [3-7].

Table 1: The comparison of the specific energy consumption for assorted methods of desalination.

\begin{tabular}{|c|c|c|c|c|c|c|c|}
\hline \multirow[b]{2}{*}{$\begin{array}{l}\text { Desalination } \\
\text { technologies }\end{array}$} & \multicolumn{2}{|c|}{ Derived Energies } & \multicolumn{2}{|c|}{$\begin{array}{c}\text { Conversion efficiency } \\
{[6,7]}\end{array}$} & \multirow[b]{2}{*}{$\begin{array}{c}\text { Primary } \\
\text { energy } \\
\left(\mathrm{kWh}_{\mathrm{pe}} / \mathrm{m}^{3}\right)\end{array}$} & \multirow[b]{2}{*}{ PPR } & \multirow[b]{2}{*}{$\begin{array}{c}\text { PPR } \\
\text { percentage } \\
\text { of TL } \\
(\mathrm{TL}=828)\end{array}$} \\
\hline & $\begin{array}{c}\begin{array}{c}\text { Electrical } \\
\text { energy } \\
\text { consumption } \\
\frac{k W h_{\text {elec }}}{m^{3}}\end{array} \\
\end{array}$ & $\begin{array}{c}\begin{array}{c}\text { Thermal } \\
\text { energy }\end{array} \\
\text { consumption } \\
\frac{k W h_{\text {ther }}}{m^{3}}\end{array}$ & $\begin{array}{c}\text { Weighted } \\
\text { exergy } \\
\text { factor for } \\
\text { Power } \\
\text { plant. } \\
\varphi_{\text {elec }}=0.476 \\
\end{array}$ & $\begin{array}{c}\text { Exergy } \\
\text { factor for } \\
\text { desalination } \\
\varphi_{\text {ther }}=29.4\end{array}$ & & & \\
\hline SWRO & 3.5 & - & \multirow{3}{*}{$\frac{1}{0.476}$} & \multirow{3}{*}{$\frac{1}{29.4}$} & 7.35 & 87.9 & $10.6 \%$ \\
\hline MED & 2.3 & 71.7 & & & 7.27 & 88.9 & $10.7 \%$ \\
\hline MSF & 3.0 & 80.6 & & & 9.04 & 71.5 & $8.6 \%$ \\
\hline$* T L=\frac{2326}{2.8}$ & $\frac{\mathrm{k} / \mathrm{kg}}{/ / \mathrm{kg}}=828$ & $5 x\left\{\varphi_{\text {elec }}\left(\frac{k V}{}\right.\right.$ & $\begin{array}{l}\left.\frac{2.8 \mathrm{~kJ}}{\mathrm{~kg}}\right] \\
2326\left\{\frac{\mathrm{kJ}}{\mathrm{kg}}\right. \\
\left.\left.\frac{\mathrm{n}_{\text {elec }}}{\mathrm{n}^{3}}\right)\right\}+\{4\end{array}$ & her $\left(\frac{k W h}{m}\right.$ & $\overline{e r})\}$ & & \\
\hline & & & Primary & $\operatorname{ergy}$ & & & \\
\hline
\end{tabular}

Since 1995, the chronological trends of PPRs for both thermally and pressure-driven processes has been improved steadily and reached the current values of 66 to 100, as shown in Figure 2 [2]. Despite the commonly held notion that the membrane-based RO method is more energy efficient than the MSF/MED, they have attained merely less than $11 \%$ of the thermodynamic limit where the best overall specific electricity consumption (SEC) of desalination is about 3 to $5 \mathrm{kWh}_{\text {elec }} / \mathrm{m}^{3}$, corresponding to 6.5 to $10 \mathrm{kWh}_{\mathrm{pe}} / \mathrm{m}^{3}$ with a weighted power plant efficiency of $47 \%$, as presented in Table 1. 


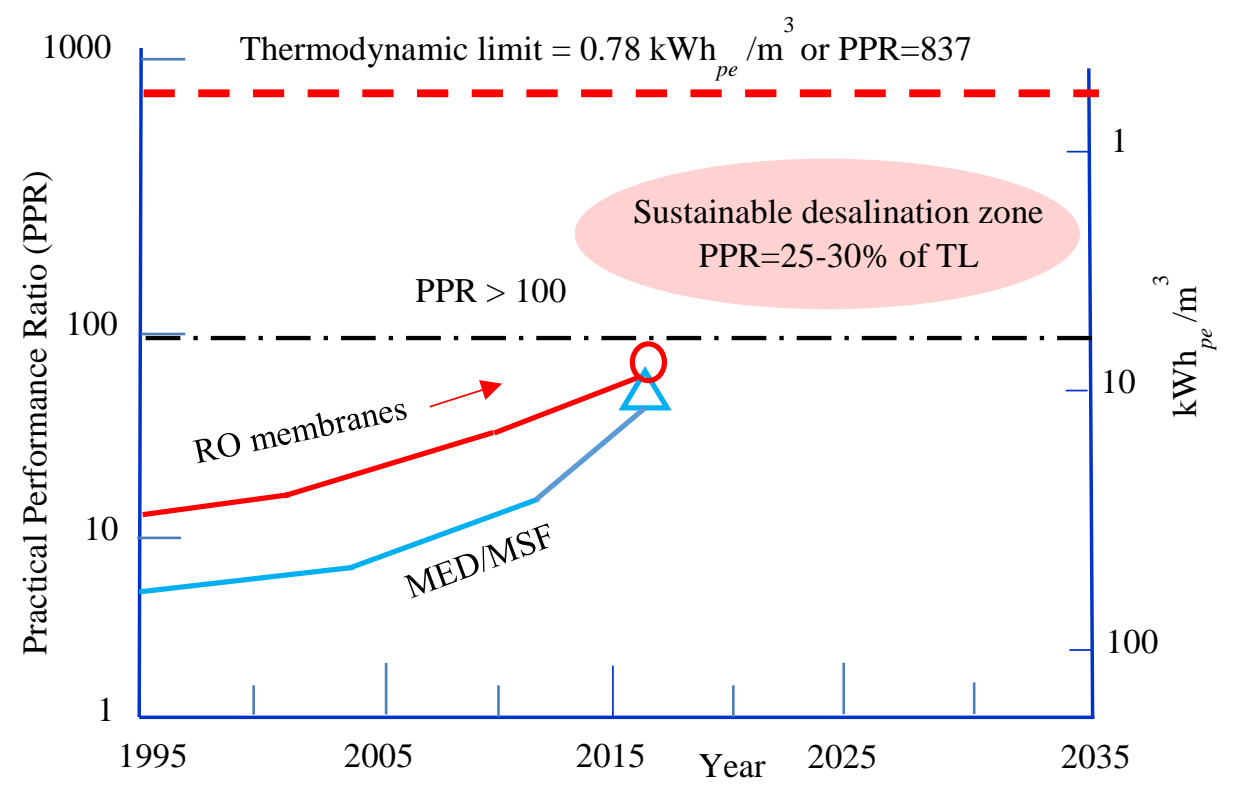

Figure 2: The chronological trends of practical performance ratio (PPR) of reverse osmosis (RO), multi-effect flashing and distillation (MSF/MED) method, expressed in terms of the primary energy consumption. The thermodynamic limit (TL) for seawater desalination is denoted by red dotted line for comparison.

Presently, with global fresh water demand of 92 million $\mathrm{m}^{3} /$ day, the associated annual carbon dioxide $\left(\mathrm{CO}_{2}\right)$ emission to the ambient is in excess of 100 Mtons [8-14]. The fresh water demand in the GCC countries, which is at $33 \%$ of the global capacity, looms to be more critical due the severe hot and dry weather conditions where the annual average precipitation is less than $80 \mathrm{~mm}$. Given the expected growth trends in local population and economic GDP of the Gulf Cooperation Council (GCC) countries, it is predicted that the global desalination capacity in the next decade will reach $170 \mathrm{Mm}^{3} /$ year, imposing a further burden on the electricity production from the fossil fuels. Although the membrane-based RO has slightly higher PR values than the thermally-driven MSF or MED, the latter methods remain the dominant in GCC countries because of the challenging seawater conditions of the Gulf [15-17].

In the past decades, there were many frequent occurrences of harmful algae blooms (HABs) in the Gulf seawater near to the Straits of Hormuz caused by the seasonal surge of nutrients, as shown in Figure 3 and they affected about $70 \%$ of the RO plants in the region $[18,19]$. 


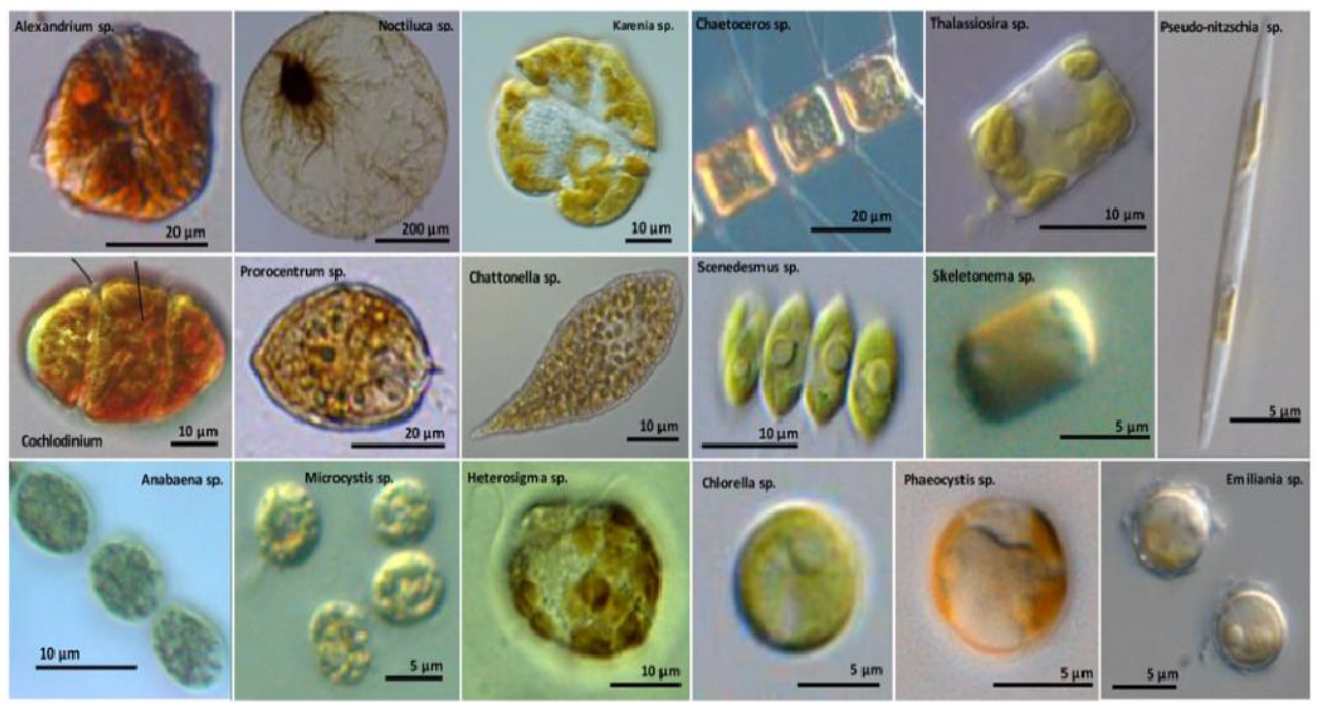

Figure 3: Common algae bloom forming species found in the GULF seawater [19].

About 60 to 70 bloom forming species out of 300 are detected hazardous to human, comprising $80 \%$ dinoflagellates and red tides as shown in Figure 3. The harmful toxin, when released from the ruptured cell wall or otherwise, has serious health hazards to humans when the toxins are ingested, such as respiratory or digestive tract problems, memory loss, seizures and skin irritation and deaths in serious cases. In one variety of the harmful toxins such as the Saxi-toxin (neurotoxin), can be 1000 times more potent than cyanide or 50 times stronger than the curare (paralyzing poison). The extent of HABs occurrences in the Straits of Hormuz has been observed from the pictures taken by Envisat's MERS instruments. In 2008 and 2013, the spread of red tides along the tip of Hormuz into the Indian Ocean are shown in the Figure 4, and the yellow circles on the map indicated the affected RO plants where their operation were forced to shutdown for a period of several weeks $[20,21]$. Such a situation is not tenable when the potable water storage capacities in these GCC countries are normally less than a week. 


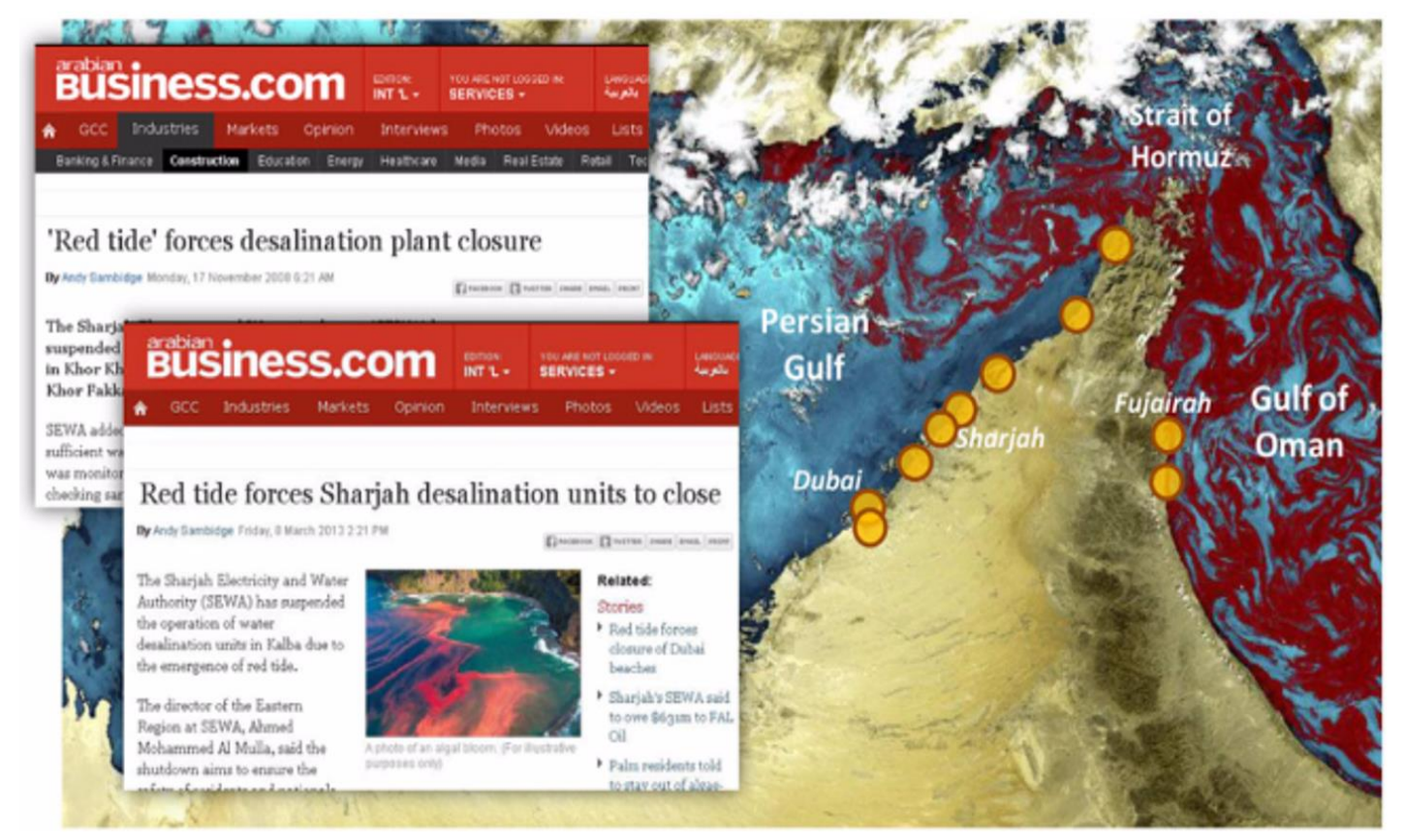

Figure 4: Press

On the other hand, the multi-stage flash (MSF) and multi-effect desalination (MED) are suited in the Gulf region due primarily to the robustness of evaporative processes. In thermal desalination, only vapor leaves the feed seawater whilst the harmful algae blooms (HABs) and high silt particles are left behind in brine solution within the evaporators, though that some traces of volatiles could be transported with water vapor.

Although thermal desalination cycles accrued much thermal energy input in evaporation processes, what if the evaporation energy for top-brine stage and the cooling energy for condenser can be supplied entirely from the renewable sources of warm and cold surface of seawater?

These renewable energy sources are readily available at 1 to 3 kilometres from the shores of certain coastal seabed bathymetry where the thermal gradient or thermocline and the cold seawater at deep sea bed are available at the same location. These renewable energy sources, warm surface water and cold deep sea are used in tandem to operate low temperature thermal desalination (LTTD) processes to produce fresh water without global warming impact. The $70 \%$ of Earth's surface, the ocean, act as a natural solar collectors to capture energy from daily solar irradiance and maintain surface water at $28-30{ }^{\circ} \mathrm{C}$ in specific tropical locations all year round. Concomitantly, the deep sea beds at 300 to $600 \mathrm{~m}$ act as an infinite supply of cold water where the temperatures hover from $10^{\circ} \mathrm{C}$ to $4^{\circ} \mathrm{C}$. Seawater temperature gradient is shown in Figure 5(a) and potential location is presented in Figures $5(\mathrm{~b}, \mathrm{c})$. 

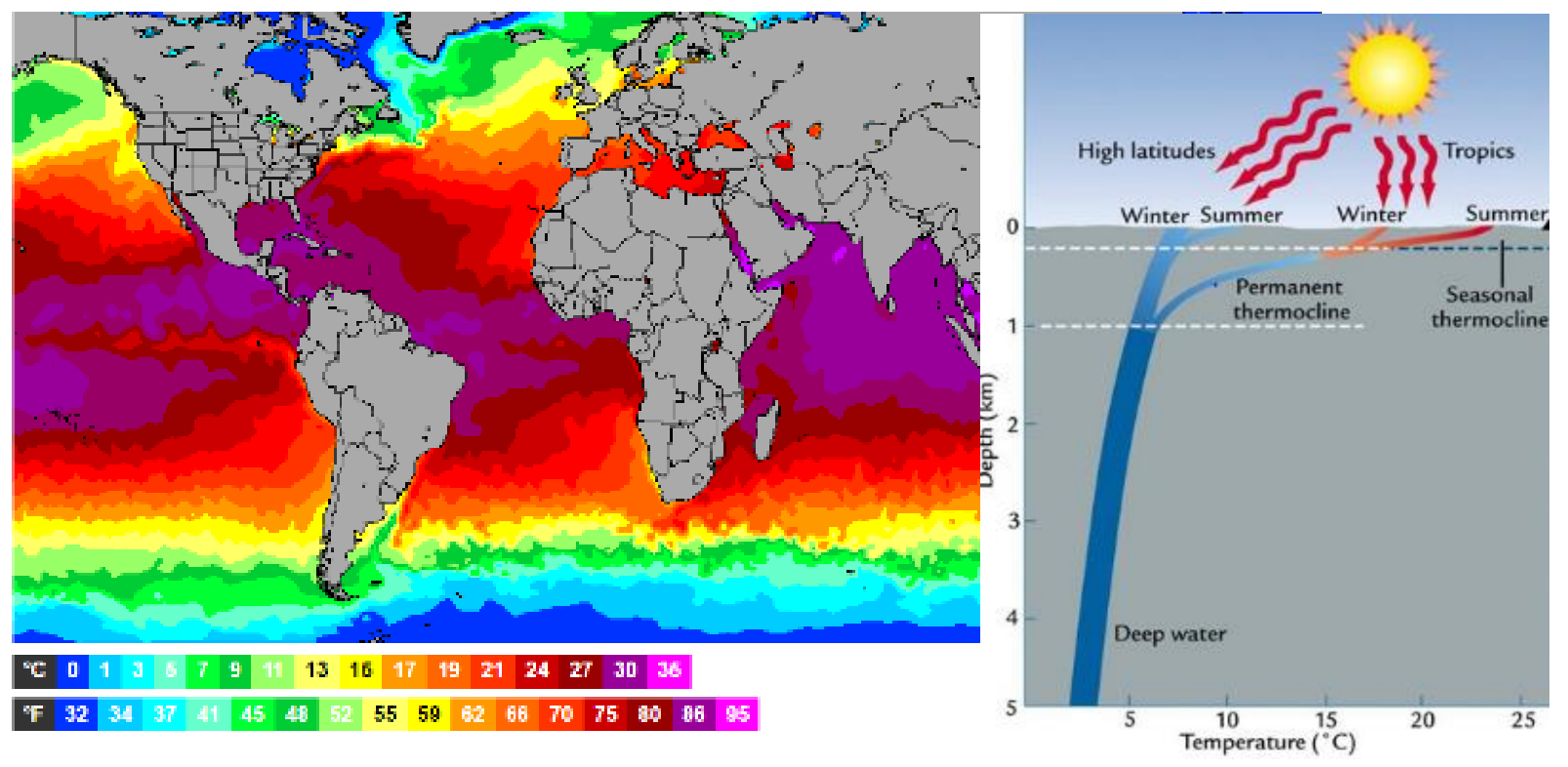

Figure 5(a): Seawater surface temperature distribution and profile change with depth.
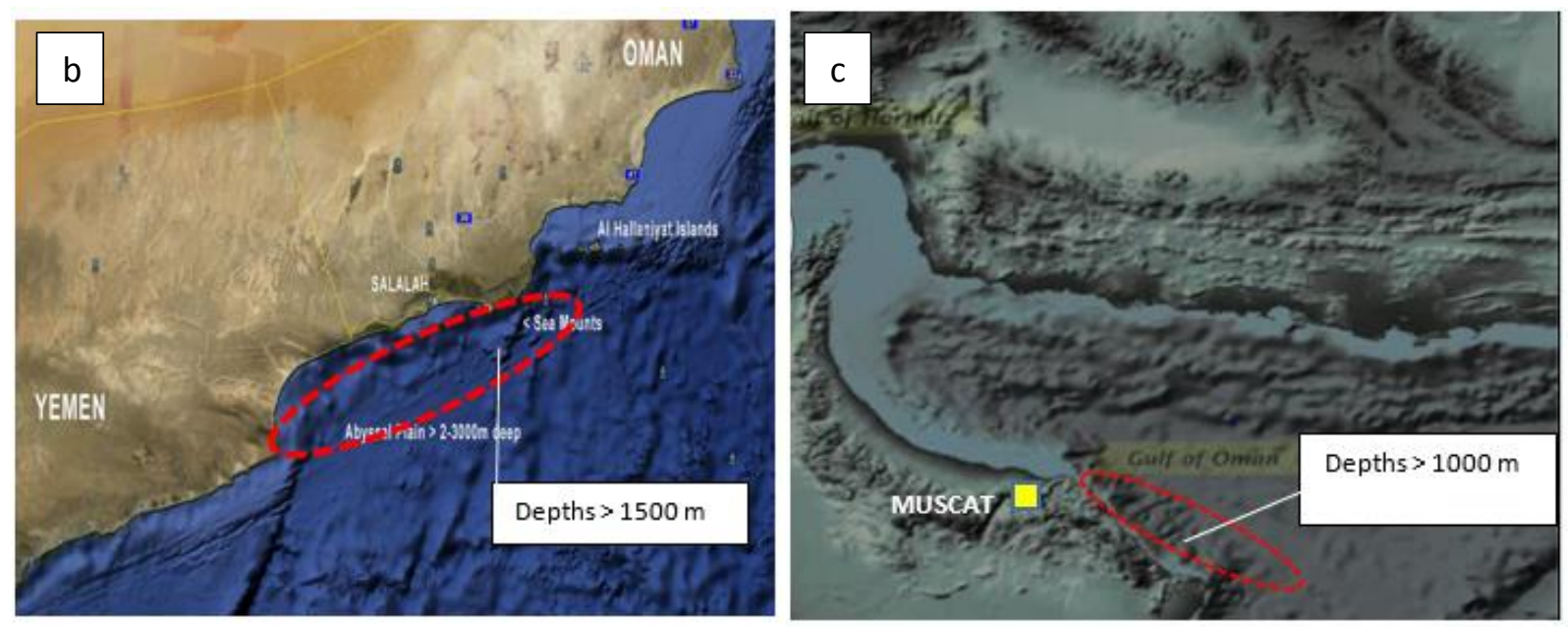

Figure 5: (b) The sea beds drop-off steeply to 1,500 m just 1-3 km off the south-eastern shores of Yamen and Oman and (c) The east cost of Oman, after Muscat, has similar steep sea bed bathymetry up to $1,000 \mathrm{~m}$.

For example, the coastal locations of Oman, Yamen, Sulawesi (Indonesia), Hawaii (USA), and Karavatti (India), have the unique sea-bed bathymetry for ST-MED operation [22-24]. The MED 
process is well proven [25-35] and it is thermodynamically suited for exploiting low temperature difference, $20^{\circ} \mathrm{C} \mathrm{K}$, available in seawater thermocline. There is boundless supply of renewable seawater thermocline energy between the tropics of Cancer and Capricorn throughout the year for sustainable production of fresh water:- The parasitic electricity is consumed by the warm and cold seawater pumps and the vacuum pump. The detailed processes of ST-MED is explained in the next section.

\section{2- $\quad$ Seawater Thermocline MED (ST-MED) Cycle}

The performance of ST-MED can be significantly improved by optimizing the evaporationcondensation stages of MED in a synergetic manner where the temperature drop per stage is well controlled to less than $3{ }^{\circ} \mathrm{C}$ to $4{ }^{\circ} \mathrm{C}$. The first stage of MED is supplied with warm surface seawater, typically varying from $28{ }^{\circ} \mathrm{C}$ to $30{ }^{\circ} \mathrm{C}$ during the diurnal-nocturnal periods whilst the condenser is fed with the cold seawater drawn from depths between $220 \mathrm{~m}$ to $600 \mathrm{~m}$ where its temperatures vary from $5{ }^{\circ} \mathrm{C}$ to $13{ }^{\circ} \mathrm{C}$, respectively. Detailed theoretical simulations model was developed as presented in Appendix 2 [36] and it was written in FORTRAN to conduct transient simulation. It show that a 4- to 6-stage MED cycle could be operated entirely with available renewable or "green" energy derived from thermocline.

Each stage of the MED is designed [37], for example, with a finite surface area of $4.0 \mathrm{~m}^{2}$ for evaporative film-boiling of seawater whilst the vapour generated in the last stage are condensed in the condenser using deep sea cold water. A fraction of the cold water is employed as seawater feed, sprayed in-parallel into all MED stages. To avoid excessive quenching at stages 1 and 2 of the MED operating with higher saturation temperatures, the feed is further heated by the warm seawater emanated from the first stage, as shown in Figure 6. The standard operation of a MED is assumed, i.e., the vapour produced at the 1st stage of MED is channelled for condensation into the tube-side of the 2 nd stage. The heat of condensation is recovered for immediate film evaporation over the tube surfaces where seawater feed are sprayed. The local saturation temperature of the subsequent stage is always lower than the preceding stage due to slight pressure drop across stages. For higher efficiency, these evaporation-condensation processes are designed for cascading operation until all the available temperature differential from the seawater thermocline is consumed, i.e., from $30{ }^{\circ} \mathrm{C}$ down to $10{ }^{\circ} \mathrm{C}$. The distillate from all MED stages are collected in a common collection header after each pressure equalization with respect to the MED chambers whilst the concentrated brine is refluxed back by gravity to the sea via a 10-m Utube arrangement. For such operation, there are only two electrically-driven pumps needed for providing warm and cold seawater circulation. Non-condensable such as entrained air in the seawater is evacuated by a vacuum pump from the condenser chamber. Vacuum pumping power can be further reduced if the brine from MED is further re-circulated as feed.

It can be seen that, other than the parasitic pumping, all thermal energy exploited by the STMED is deemed non-polluting as it is derived from the renewable solar in the form of 
thermocline energy of seawater. Hence, the performance ratio is expected to be high because of the low consumption of fossil-based energy, namely, the pumping power of the cycle.

As the concept of LTTD is not new, many LTTD pilot plants have been attempted by exploiting the energy from thermal-gradient of seawater [38-43]. For example, the National Energy Laboratory of Hawaii and the National Institute of Ocean Technology (NIOT) of India have attempted to use ocean thermal energy either for power or desalination. Since 2005, the LTTD pilot plant of NOIT was most successful, producing $100 \mathrm{~m}^{3}$ per day fresh water for Kavaratti island in the Indian Ocean which was commissioned at a cost of INR 50 million (US\$1.04 million). Unfortunately, the desalination plant at Kavaratti employed only a single-stage MED, operating between the thermocline energy from 28 to $10^{\circ} \mathrm{C}$ at a depth of $220 \mathrm{~m}$ [44]. Besides the ST-MED configuration, the MED can be hybridized or integrated with other thermally-driven cycles such as the adsorption cycle to recover condensation heat of desorbed vapour for achieving better performance ratio and energy sustainability [45-48].

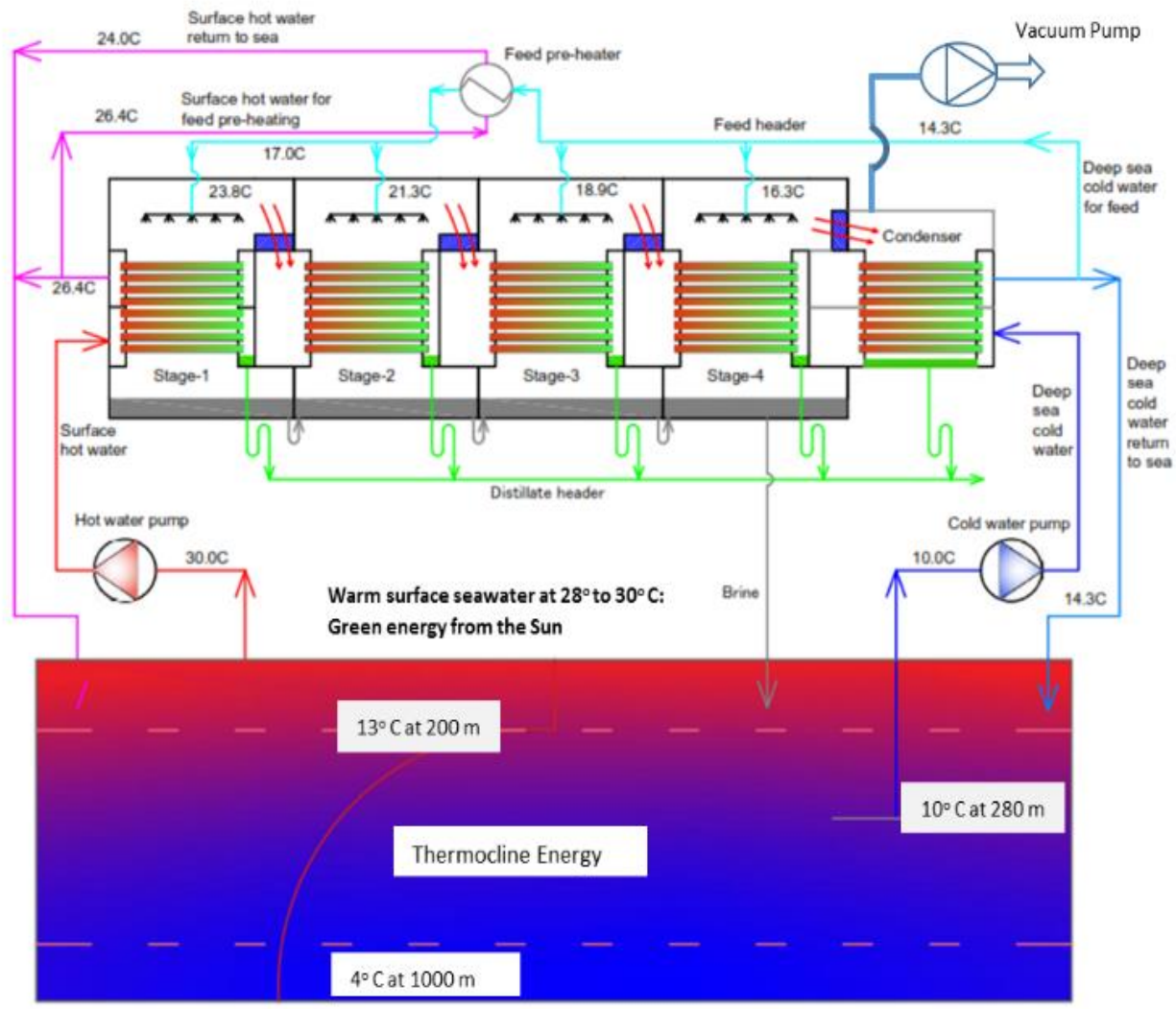

Figure 6: Process schematic of thermocline operated ST-MED cycle designed to produce $18 \mathrm{~m}^{3} /$ day. 


\section{3- $\quad$ Results and Discussion}

Figures 7(a) show the temperature profiles of surface hot water, deep sea cold water and MED components starting from ambient condition. With operational temperature differential of $20{ }^{\circ} \mathrm{C}$, only 4 stages are sufficient for effective utilization of available thermal energy. Surface seawater at $30{ }^{\circ} \mathrm{C}$ is supplied to the first stage and the outlet is channelled feed pre-heater to reheat the cold feed that sprayed into stages 1 and 2 of MED. Similarly, cold seawater at $10{ }^{\circ} \mathrm{C}$ is drawn from a depth of $600 \mathrm{~m}$ to circulate through the condenser tubes for its vapor to be condensed on the outer surfaces. A small portion of cold seawater is supplied to the MED spray system as a feed and rest is discharged back to the sea. Given the design, the inter-stage temperature differential may vary from $2{ }^{\circ} \mathrm{C}$ to $2.5^{\circ} \mathrm{C}$ depending on the amount of reheating of the spray feed. It can be seen that proposed MED system can exploit very low temperature differential thermal energy to produce fresh water.

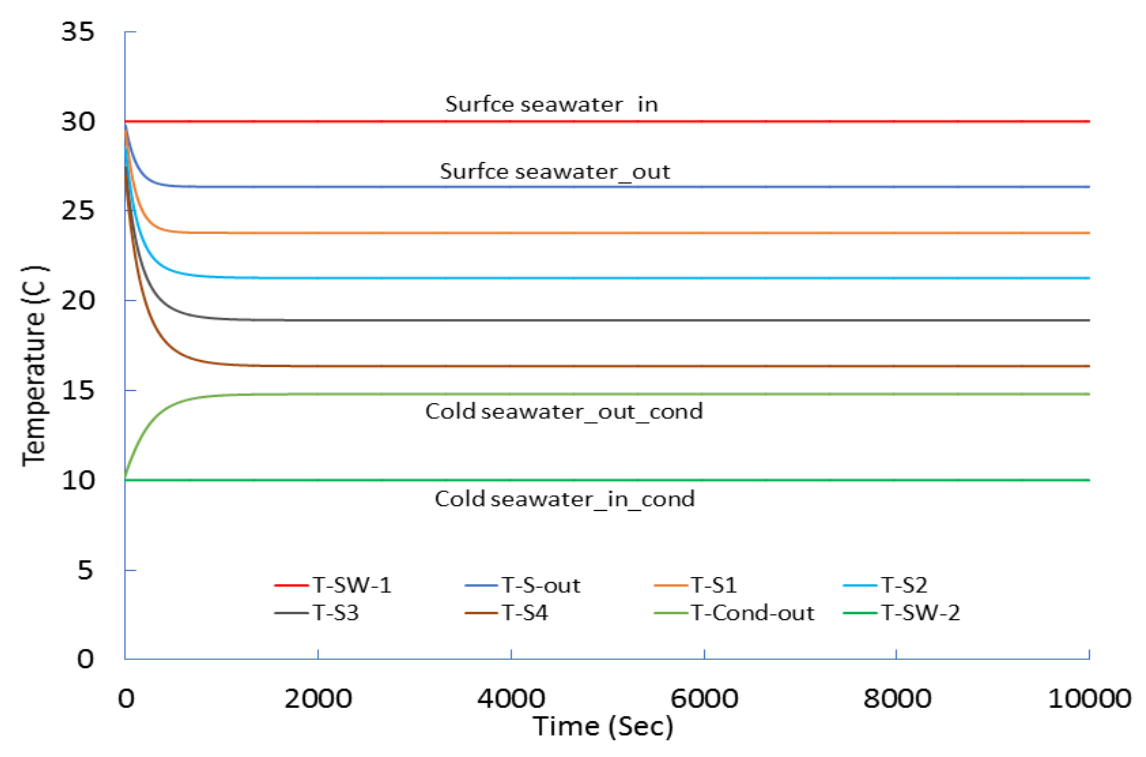

Figure 7(a): Temperature profiles of vapour in the 4 MED stages and the temperatures of inlet and outlet seawater from the vapour generator and condenser.

Figures 7(b) shows distillate production profiles of all four stages and it can be seen that total 8.6 LPM production can be achieved. The brine concentration was increase to 47,000ppm from 35,000ppm feed supplied ppm, as shown in Figure 7(c). 


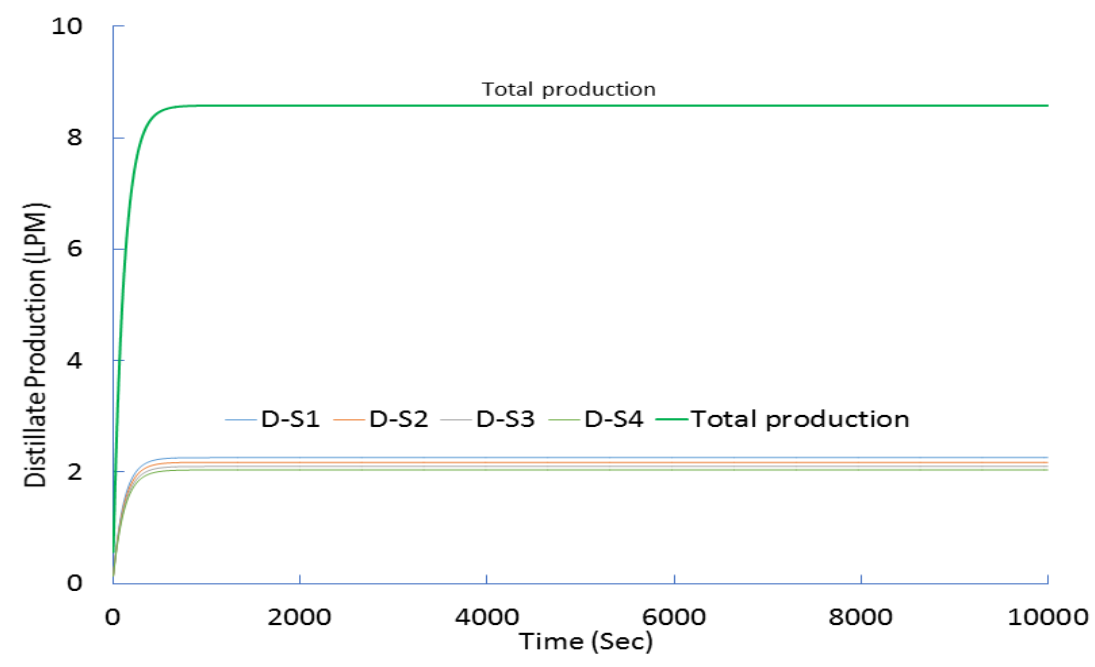

Figure 7(b): Distillate production profiles of 4 MED stages and the overall water production.

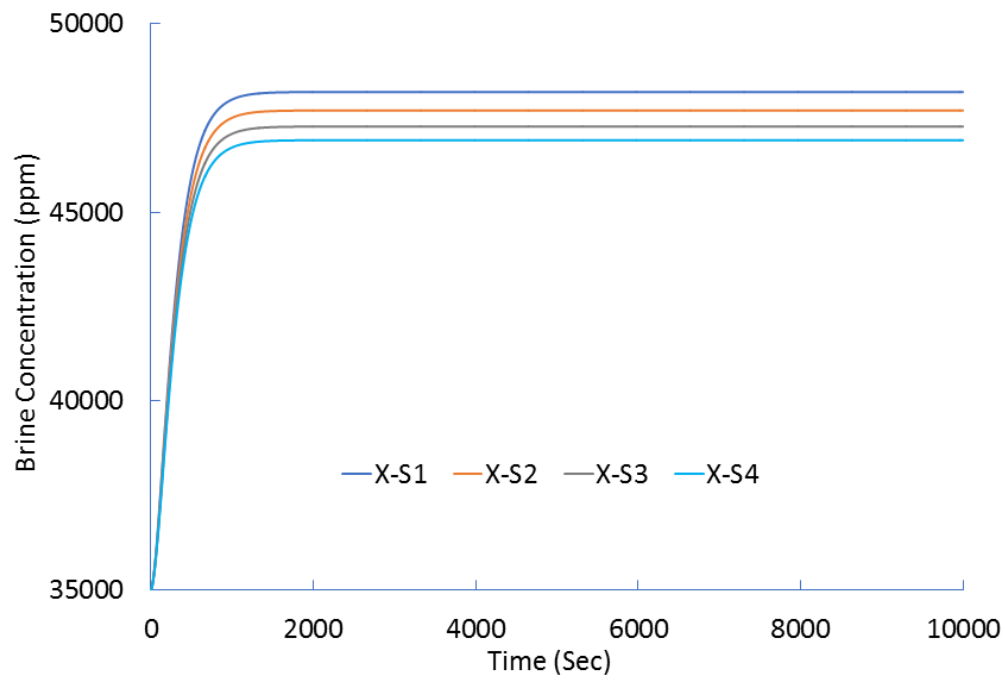

Figure 7(c): Brine concentration profiles of all 4 MED stages. Feed was supplied at 35,000ppm.

For comparison analysis, we considered four cases of ST-MED at assorted seawater depths (200 $\mathrm{m}, 280 \mathrm{~m}, 380 \mathrm{~m}$ and $600 \mathrm{~m}$ ) for cold water supplies. The total parasitic pumping and vacuuming power are computed and the results are summarized in Table 2. 
Table 2: Summary of results of four cases of MED operating at assorted temperature differentials from thermocline energy

\begin{tabular}{|c|c|c|c|c|c|c|c|}
\hline $\begin{array}{l}\text { Operation } \\
\text { range }\end{array}$ & $\begin{array}{l}\text { No. of } \\
\text { MED } \\
\text { stages }\end{array}$ & $\begin{array}{l}\text { Water } \\
\text { production } \\
\text { (LPM) }\end{array}$ & $\begin{array}{c}\text { Condenser } \\
\text { chilled } \\
\text { water } \\
\text { (LPM) }\end{array}$ & $\begin{array}{l}\text { Depth } \\
\text { (m) }\end{array}$ & $\begin{array}{l}\text { Pipe } \\
\text { friction } \\
\quad(\mathrm{m})\end{array}$ & $\begin{array}{l}\text { Pumping power* } \\
\qquad \mathrm{kW}_{\text {elec }} \\
\left(\mathrm{kWh}_{p e} / \mathrm{m}^{3}\right)\end{array}$ & PPR \\
\hline $30{ }^{\circ} \mathrm{C}-5{ }^{\circ} \mathrm{C}$ & 6 & $\begin{array}{c}12.6 \\
\left(18.15 \mathrm{~m}^{3} / \text { day }\right)\end{array}$ & 240.0 & 600 & 7.42 & $\begin{array}{c}1.51 \\
(4.28)\end{array}$ & 152.5 \\
\hline $30{ }^{\circ} \mathrm{C}-8{ }^{\circ} \mathrm{C}$ & 5 & $\begin{array}{c}10.6 \\
\left(15.3 \mathrm{~m}^{3} / \mathrm{day}\right)\end{array}$ & 240.0 & 380 & 4.68 & $\begin{array}{l}1.23 \\
(4.15) \\
\end{array}$ & 157.3 \\
\hline $30{ }^{\circ} \mathrm{C}-10{ }^{\circ} \mathrm{C}$ & 4 & $\begin{array}{c}8.6 \\
\left(12.4 \mathrm{~m}^{3} / \text { day }\right)\end{array}$ & 246.0 & 280 & 3.42 & $\begin{array}{c}0.99 \\
(4.13) \\
\end{array}$ & 158.0 \\
\hline $30{ }^{\circ} \mathrm{C}-13{ }^{\circ} \mathrm{C}$ & 3 & $\begin{array}{c}6.6 \\
\left(9.5 \mathrm{~m}^{3} / \text { day }\right) \\
\end{array}$ & 252.0 & 220 & 2.66 & $\begin{array}{c}0.78 \\
(4.20) \\
\end{array}$ & 155.4 \\
\hline \multicolumn{8}{|c|}{$\begin{array}{l}\text { *For pumping power calculation, the following assumptions ar } \\
1 \text {-Pipe length for friction is } 1.25 \text { times of the depth. } \\
2 \text {-MED plant platform elevation is } 15.0 \mathrm{~m} \text { above the sea level. } \\
3 \text {-Vacuum pump to water pump power is } 60 \%: 40 \% \text {. } \\
4 \text { - Exergetic utilization of primary energy by (i) gas turbines f }\end{array}$} \\
\hline
\end{tabular}

Consequently, the number of stages of MED may change from 3 stages at $13^{\circ} \mathrm{C}$ (depth of $220 \mathrm{~m}$ ) to 6 stages at $5^{\circ} \mathrm{C}$ (depth of $600 \mathrm{~m}$ ) and the pumping of seawater from such depths may affect the total pipe friction head (typically at $3 \mathrm{~m}$ to $5 \mathrm{~m}$ ) needed to move chilled water flow rates of 7 to $13 \mathrm{~L} / \mathrm{min}$. Based on the estimated electricity consumption for parasitic pumping, the primary energy is calculated considering power plant overall efficiency $47 \%$ and then PPR for the four cases are computed using Equation 1 as shown below. It is noted that the best $\mathrm{PPR}=158$, corresponding to $18.8 \%$ of the thermodynamic limit (TL), is achieved by ST-MED cycle;- one of the highest ever reported for seawater desalination. The system performance can be further improved by utilizing solar collectors to increase surface temperature. This is a realistic and achievable target for achieving the goals of sustainable desalination, as plotted on the chart for PPR in Figure 8.

$$
P P R=\frac{2326\left\{\frac{k J}{k g}\right\}}{3.6 x\left\{\varphi_{\text {elec }}\left(\frac{k W h_{\text {elec }}}{m^{3}}\right)\right\}+\left\{\varphi_{\text {ther }}\left(\frac{k W h_{\text {ther }}}{m^{3}}\right)\right\}}
$$

Primary Energy 


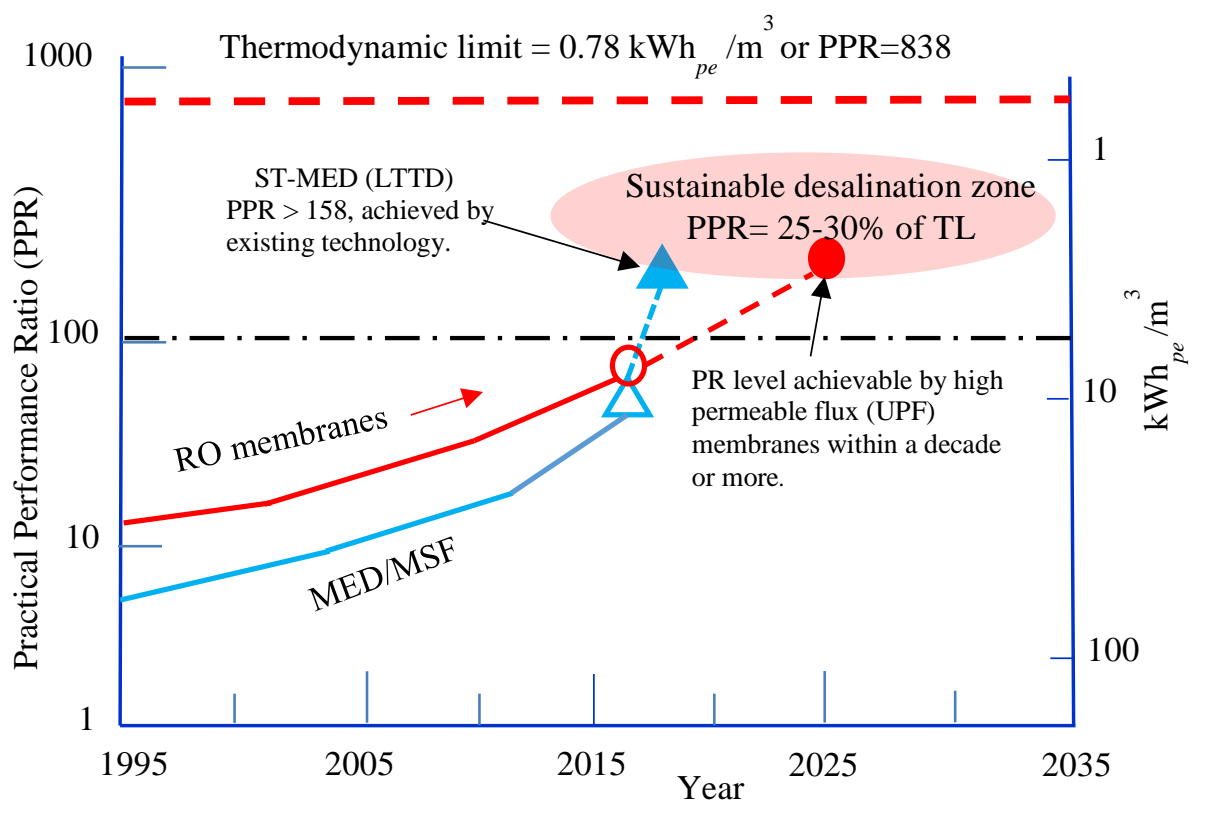

Figure 8: The ST-MED cycle has 2 folds improvement in the energy efficiency over the existing thermally-driven efficiency. It meets the goals of sustainable desalination where the achieved PPR is greater than 158 or about $18.8 \%$ of the thermodynamic limit (TL).

The thermal energy input from seawater thermocline is neatly utilized without any additional capital cost of thermal collectors or chillers. It should also be emphasized that the technology of ST-MED is well proven and readily available for installation. Even with recent successes on the performance of ultra-permeable flux (UPF) membranes [20] such as the aquaporin and graphene, their development are still at the infancy stage and may take a long time to attain the same commercial viability needed for sustainable seawater desalination.

\section{Conclusions}

The low efficiency of today's practical desalination methods hover around $8-11 \%$ of the thermodynamic limit (TL) and they are obviously unsustainable for future desalination particularly when the demand for potable water is increasing annually at a rate of $6.5 \%$. However, we have demonstrated that the ST-MED processes, powered by the seawater thermocline energy with zero global warming potential, has the ability to operate efficiently within a $20^{\circ} \mathrm{C}$ temperature difference between the warm surface seawater and the cold seawater from deep sea-bed. This form of "green energy" source is supplied from the renewable solar irradiance the whole year round without the need of thermal collector or chiller infrastructure. 
Only a minor parasitic electricity is consumed for warm and cold water pumping, as well as the removal of non-condensable from the seawater feed. The adoption of fossil-fuel based primaryenergy in the evaluation of PPR provides a fair platform to conduct a cross comparison of all desalination processes. However, the consumption of renewable energy sources in desalination is exempted from PR as it is non-polluting. Thus, the ST-MED cycle has the best PPR of 158 or nearly $19 \%$ of TL and it meets the desired goals of sustainable and environment-friendly desalination.

\section{Acknowledgements}

The research reported in this paper was supported by King Abdullah University of Science and Technology (KAUST), Saudi Arabia, Project \# 7000000411.

\section{References}

1. Noreddine Ghaffoura, Jochen Bundschuhb, Hacene Mahmoudic and Mattheus F.A. Goosen, Renewable energy-driven desalination technologies: A comprehensive review on challenges and potential applications of integrated systems, Desalination 356 (2015) 94-114.

2. Lienhard, J. H. et al. Low Carbon Desalination: Status and Research, Development, and Demonstration Needs. Report of a workshop conducted at the Massachusetts Institute of Technology in association with the Global Clean Water Desalination Alliance. (2016).

3. Noreddine Ghaffour, Sabine Lattemann, Thomas Missimer, Kim Choon Ng, Shahnawaz Sinha and Gary Amy, Renewable energy-driven innovative energy-efficient desalination technologies Applied Energy 136 (2014) $1155-1165$.

4. Noreddine Ghaffour, Thomas Missimer and Gary Amy, Technical review and evaluation of the economics of water desalination: Current and future challenges for better water supply sustainability. Desalination 309, 197207 (2013).

5. Menachem Elimelech and William A. Phillip, The Future of Seawater Desalination: Energy, Technology, and the Environment, Science 333, 712 (2011).

6. N. Lior, "The Second Law of Thermodynamics and Entropy", chapter 44, Handbook of Engineering, E. Dorf, Ed., CRC Press, 1996, pp. 462-478.

7. N. Lior, "Thoughts about future power generation systems and the role of exergy analysis in their development", Energy Conversion and Management J., vol. 43, 2002, pp. 1187-1198.

8. Concept Chapter, Global Clean Water Desalination Alliance "H20 minus CO2". http://www.diplomatie.gouv.fr/fr/IMG/pdf/global_water_desalination_alliance_1dec2015_cle8d61cb.pdf.

9. Redrawing the Energy-Climate map, World Energy Outlook Special Report, International Energy Agency (IEA) (2013). www.worldenergyoutlook.org/aboutweo/workshops

10. Friedlingstein, P. et al. Persistent growth of $\mathrm{CO} 2$ emissions and implications for reaching climate targets. Nature Geoscience 7, 709-715 (2014).

11. COP 21: UN climate change conference, Paris (2015) http://www.cop21.gouv.fr/en/why-2c/

12. Francey, R. J. et al. Atmospheric verification of anthropogenic $\mathrm{CO} 2$ emission trends. Nature Climate Change 3, 520-524 (2013).

13. Raupach, M. R., Quéré, C. L., Peters, G. P. \& Canadell, J. G. Anthropogenic CO2 emissions. Nature Climate Change 3, 603-604 (2013).

14. Carbon Dioxide Information Analysis Center, Oak Ridge National Laboratory, Center for climate and Energy Solutions, (2016).

15. Muhammad Wakil Shahzad and Kim, Kim C Ng On the road to water sustainability in the Gulf, Nature Middle East, (2016), doi: 10.1038/nmiddleeast.2016.50. 
16. Muhammad Wakil Shahzad, Kyaw Thu, Kim Choon Ng and Chun WonGee, Recent development in thermally activated desalination methods: Achieving an energy efficiency less than $2.5 \mathrm{kWhelec} / \mathrm{m} 3$, Desalination and Water Treatment, 57(2016) 7396-7405.

17. Muhammad Wakil Shahzad, Kyaw Thu, Yong-deuk Kim, Kim C Ng, An Experimental Investigation on MEDAD Hybrid Desalination Cycle, Applied Energy 148 (2015) 273-281.

18. Adnan Al-Azri, Sergey Piontkovski, Khalid Al-Hashmi, Hamed Al-Gheilani, Harib Al-Habsi, Salem AlKhusaibi \& Nasser Al-Azri, The occurrence of algal blooms in Omani coastal waters, 15 (2012) 56-63.

19. L.O. Villacorte, S.A.A. Tabatabai, N. Dhakal, G. Amy, J.C. Schippers and M.D. Kennedy, Algal blooms: an emerging threat to seawater reverse osmosis desalination, Desalination and Water Treatment, 55 (2015) 26012611.

20. Zhao J., Temimi M., and Ghedira H., Characterization of harmful algal blooms (HABs) in the Arabian Gulf and the Sea of Oman using MERIS fluorescence data, ISPRS Journal of Photogrammetry and Remote Sensing,101 (2015) 125-136.

21. Mryam R. Al Shehhi, Imen Gherboudj and Hosni Ghedira, An overview of historical harmful algae blooms outbreaks in the Arabian Seas, Marine Pollution Bulletin, 86 (2014) 314-324.

22. Y. Ikegami, The Advanced Technology and Future Prospect of OTEC for Island, World Sea Temperatures, https://www.iea.org/media/workshops/2015/egrdoct/10Ikegami_SagaU.pdf (Date of access: 6th August 2016)

23. Malavika Vyawahare, Cod Could Recover in Warming Waters, Scientific America, http://www.scientificamerican.com/article/cod-could-recover-in-warming-waters/ (Date of access: 10th August 2016)

24. P. V. S. Sistla, G. Venkatesan, P. Jalihal, S. Kathiroli, Proceedings of The Eighth ISOPE Ocean Mining Symposium Chennai, India, 2009, September 20-24. Proceedings of The Eighth (2009) ISOPE Ocean Mining Symposium, ISBN 978-1-880653-75-3; ISSN 1946-0066.

25. Miller, J. E. Review of water resources and desalination technologies. SAND report 2003-0800 (2003).

26. Darwish, M. A. Thermal Analysis of Vapor Compression Desalination System. Desalination 69, 275-295 (1988).

27. Al-Radif, A. Review of various combinations of a multiple effect desalination plant (MED) and a thermal vapour compression unit. Desalination 93, 119-125 (1993).

28. Eltawil, M. A. et al. Renewable energy powered desalination systems: technologies and economics-state of the art. Twelfth International Water Technology Conference, IWTC12 2008 Alexandria, Egypt (2008).

29. Mabrouk, A. N. and Fath, H. E. S. Technoeconomic study of a novel integrated thermal MSF-MED desalination technology. Desalination 371, 115-125 (2015).

30. El-Nashar, A.M. The economic feasibility of small solar MED seawater desalination plants for remote arid areas. Desalination 134, 173-186 (2001).

31. Milow, B. and Zarza, E. Advanced MED solar desalination plants. Configurations, costs, future - seven years of experience at the Plataforma Solar de Almeria (Spain). Desalination 108 (1-3), 51-58 (1997).

32. Reddy, K. V. and Ghaffour, N. Overview of the cost of desalinated water and costing methodologies. Desalination 205 (1-3), 340-353 (2007).

33. Hamed, O. A. Successful Operation of MED/TVC Desalination Process at TBT of $125 \mathrm{oC}$ Without Scaling, IDA World Congress-Dubai, UAE, November 7-12.

34. Hamed, O. A. Development of 10 MIGD MED-TVC Distiller within the Context of Tri-hybrid NF/RO/MED Configuration", IDA World Congress, Perth, Western Australia, September 4-9. (2011).

35. Operation management device for a vaporization device, fresh water generator provided with operation management device, and operation management method and fresh water-generating method for vaporization devices. Japanese Patent \# 4743727. (2011).

36. Muhammad Wakil Shahzad, The hybrid multi-effect desalination (MED) and the adsorption (AD) cycle for desalination, $\mathrm{PhD}$ thesis, National University of Singapore.

37. Muhammad Wakil Shahzad, Aung Myat, Chun Won Gee and Kim Choon Ng, Bubble-assisted film evaporation correlation for saline water at sub-atmospheric pressures in horizontal-tube evaporator, Applied Thermal Engineering 50 (2013) 670-676,

38. Haruo Uehara, Akio Miyara, Yasuyuki Ikegami and Tsutomu Nakaoka, Performance Analysis of an OTEC Plant and a Desalination Plant Using an Integrated Hybrid Cycle, Journal of Solar Energy Engineering 118, 115-122 (1996).

39. Ocean Thermal Energy Conversion, Technology Brief, International Renewable Energy Agency Report 2014.

40. Penney TR and Bharathan D, Power from the sea. ScientiTc American 256(1): 86-92 (1987). 
41. Takahashi PK, Project blue revolution. Journal of Energy Engineering 122(3): 114-124 (1996).

42. Vega LA and Nihous GC, Design of a 5 MW OTEC pre-commercial plant. Proceedings Oceanology 94: 5 (1994).

43. Claude G. Power from the Tropical Seas, in Mechanical Engineering 52(12),1039-1044 (1930).

44. First ever low temperature thermal desalination plant for producing portable water by Indian scientists. http://www.globalislands.net/userfiles/_india_lakshadweep3.pdf (accessed on Aug 01, 2016).

45. Muhammad Wakil Shahzad, Kyaw Thu and Kim, Kim C Ng, A Waste Heat Driven hybrid ME+AD Cycle for Desalination, Water Technology, Royal Society of Chemistry, Environmental Sciences, Water Research \& Technology, (2016) doi: 10.1039/C5EW00217F

46. Kim Choon Ng, Kyaw Thu, Seung Jin Oh, Li Ang, Muhammad Wakil Shahzad and Azhar Bin Ismail, Recent developments in thermally-driven seawater desalination: Energy efficiency improvement by hybridization of the MED and AD cycles, Desalination 356 (2015) 255-270.

47. Muhammad Wakil Shahzad, Kim Choon Ng, Kyaw Thu, Bidyut Baran Saha and Won Gee Chun, Multi Effect Desalination and Adsorption Desalination (MEDAD): A Hybrid Desalination Method, Applied Thermal Engineering 72 (2014) 289-297.

48. Kim Choon NG, Kyaw Thu, Muhammad Wakil Shahzad and WonGee Chun, Progress of adsorption cycle and its hybrid with conventional MSF/MED processes in the field of desalination, International Desalination Association (IDA) Journal of Water Desalination and Reuse, 6-1 (2014) 44-56 